This PDF is a selection from a published volume from the National Bureau of Economic Research

Volume Title: Perspectives on the Economics of Aging

Volume Author/Editor: David A. Wise, editor

Volume Publisher: University of Chicago Press

Volume ISBN: 0-226-90305-2

Volume URL: http://www.nber.org/books/wise04-1

Conference Date: May 17-20, 2001

Publication Date: June 2004

Title: Socioeconomic Status, Nutrition, and Health among the Elderly

Author: Robert T. Jensen

URL: http://www.nber.org/chapters/c10347 


\title{
Socioeconomic Status, Nutrition, and Health among the Elderly
}

\author{
Robert T. Jensen
}

\subsection{Introduction}

There has been a great deal of research on the relationship between socioeconomic status (SES) and health. ${ }^{1}$ This relationship is of interest for several reasons; first, there is increasing recognition that in assessing living standards and well-being in a society, and its distribution among members, measures such as health may represent more appropriate indicators than income or expenditure. Second, understanding the relationship between SES and health is important because it can shed light on what may be a self-reinforcing cycle of poverty; low SES leads to worse health, which in turn reduces earnings capacity.

Much of the literature has focused on adults (especially those of working-age), though there has recently been increasing attention paid to children (Case et al. 2002; Meara 2001; Jensen and Richter 2001) and the elderly (Hurd, McFadden, and Merrill 1999; Jensen and Richter 2003, Smith and Kington 1997a,b). For the elderly, the health-SES relationship is particularly important because of increasing life expectancies, increasing fragility of many pension and social security systems throughout the world, and declines in extended families and traditional systems of support for the elderly.

In this paper, we apply data from a nationally representative householdlevel survey to explore the relationship between health and SES for the

Robert T. Jensen is associate professor of public policy at the John F. Kennedy School of Government, Harvard University, and a faculty research fellow of the National Bureau of Economic Research.

I would like to thank David Cutler, Lindsey Knapp, and Kaspar Richter for comments, suggestions, and assistance.

1. For summaries of this vast literature, see Feinstein 1993 and Smith 1999. 
elderly in Russia. In doing so, we have two main objectives; first, we explore the basic relationship, which is valuable because there has been little evidence on the health-SES relationship for transition economies. Further, we add to the literature by presenting evidence from a variety of measures of health and health risk factors, including measurements of blood pressure, weight, and height conducted by trained enumerators, as well as nutrient intake derived from twenty-four- and forty-eight-hour food intake diaries. Therefore, we need not rely exclusively on self-reports of health status, where response choices may have different interpretations for different people (as in self-reported overall health status), or where there may be problems of differential reporting by SES (for example, due to differential knowledge or awareness of health conditions). We use these data to show that the relationship between health and SES in Russia can't be adequately described by simple statements, such as the poor are less healthy than the rich; although, on net, the rich are healthier than the poor in some overall sense, there are important ways in which the rich face greater health risks.

But the most interesting questions in the study of the relationship between health and income, and the biggest challenges, involve trying to decompose the health differentials into the root causes. As others have noted, there are numerous channels through which the two could be linked; first, SES could affect health through the purchase of inputs that produce health (medical services, nutrition, safe and clean living environment, for example). The poor may also have more stress due to, say, greater economic volatility and uncertainty, and this greater stress could lead to worse health directly or through changes in health-related behaviors. It is also quite possible that causality runs in the opposite direction, where health affects earnings capacity and thus SES. Finally, it could also be that there are factors which cause both low SES and poor health (for example, rates of time preference or attitudes towards risk).

Therefore, our second objective is to narrow down and focus on one particular mechanism - nutrition - through which SES may affect health. The role of nutrition as a factor in the differential health status between rich and poor is often overlooked when examining middle- and upper-income countries because widespread hunger and starvation, even among the poorest, have largely been eliminated, and in fact widespread obesity is considered a greater public health concern. However, nutrition must be viewed as more complex than hunger or simply sufficient caloric intake. In particular, there are important micronutrients beyond calories that are important for good health, especially for the elderly. And the intake of these nutrients may be sensitive to income, as the lowest cost staple foods in most countries (for example, bread or rice) may yield sufficient "bulk" or calories, but (unless fortified) may have low levels of vitamins, minerals, and protein. On the other hand, these foods tend to be low in fat, cholesterol, and sodium, compared to foods which may be more expensive and eaten in larger quantities by the 
rich, for example, meat. Therefore, it is quite possible that nutrition plays a role in the relationship between health and SES, even in countries where calorie malnutrition is scarce and obesity is widespread.

We use detailed data on food intake to analyze nutrient intake for elderly Russians and how it varies with income, and the consequences for health and the relationship between health and SES. We do so by exploring (1) differences in the diets of the rich and poor, (2) how differences in diet translate into differences in nutrient intake, and (3) the impact of nutrient intake on health.

\subsection{The "Health-SES" Gradient}

We begin by documenting the relationship between SES and health in Russia. We do not, however, attempt to deal with the extremely important issue of reverse causality, that is, determining whether low SES causes bad health or vice versa, or both - a problem that plagues all studies of health and SES. Thus, the results should not be seen as suggesting causality, only establishing an empirical relationship in which there is much interest. Some studies have attempted to overcome this problem using exogenous changes in the income of the elderly (Case, chap. 7 in this vol.; Jensen and Richter 2003). However, in the present case we have no such exogenous variation.

\subsubsection{The Data}

We use data from various rounds of the Russian Longitudinal Monitoring Survey (RLMS), a nationally representative survey of approximately 4,000 households collected between 1992 and 1998. ${ }^{2}$ The data are wellsuited to the present purposes, containing detailed information on income, expenditures, and a variety of measures of health. For the later rounds of the survey there is also a twenty-four- or forty-eight-hour food recall diary, where all individuals report everything they have eaten. Furthermore, trained enumerators administered medical measurements during the surveys, including measuring weight and height, hip and thigh circumference, and blood pressure. ${ }^{3}$

For assessing health status and health risk factors, we analyze systolic and diastolic blood pressure (which can be used to assess hypertension, a leading factor in heart attack and strokes), as well as construct the body mass index (BMI), ${ }^{4}$ which is an important predictor of mortality. In addition, we consider the following set of health indicators: self-assessed

2. The survey is coordinated by the Carolina Population Center at the University of North Carolina at Chapel Hill. Further description of the data can be found at www.cpc.unc.edu/ projects/rlms/rlms_home.html.

3. Blood pressure measurements were taken three times in order to adhere to the clinical standard.

4. BMI is weight (in kilograms) divided by squared height (in meters). 
health, which is the response to a question asking the respondent to evaluate their overall health, with possible responses ranging from 1 to $5(1=$ very good; $2=$ good; $3=$ average; $4=$ bad; $5=$ very bad). We also use an indicator for whether the respondent reports in the past twelve months having experienced strong chest pains lasting half an hour or more. Finally, we construct an index of the respondent's ability to perform various activities of daily living (ADL). The ADL index ranges from 0 to 50, with the responses from ten questions about specific activities scored on a scale of 1 to 5 , where the possible responses represent 1 (not at all difficult); 2 (slightly difficult); 3 (somewhat difficult); 4 (very difficult, but possible); and 5 (cannot do it). Thus, a higher score indicates greater functional limitations. Activities included are run one kilometer; walk one kilometer; walk 200 meters; walk across a room; sit for two hours; stand up after sitting; climb several flights of stairs; climb one flight of stairs; lift and carry a weight of about five kilograms; and squat, crouch or kneel.

\subsubsection{The Gradient}

Table 8.1 presents evidence on the gradient between health and SES. To represent SES, we divide the sample of persons aged sixty and older into quartiles of income per capita (we make no adjustments for economies of scale or adult equivalents because there is no rigorous theoretical basis or obvious choice for specific adjustment factors).

The initial evidence from Russia is comparable to what is found elsewhere; for both men and women, on measures like self-assessed health, ADL limitations, and whether the person was ill in the past thirty days, the poor are less healthy than the rich. Elderly men and women in the highest income quartile report better health status $(0.3$ for men and 0.2 for women, on a five point scale) than individuals in the lowest quartile. The wealthiest also report fewer physical limitations; for men, the ADL index is almost five points lower for individuals in the upper quartile. Because the minimum score for each of the ten areas of functioning is 1 , this indicates that the wealthiest, on average, are half a point better able to perform every task, on a scale of 1 to 5 . For women, the gradient is smaller but still present. Again, it should be emphasized that causality could run in either direction (or both directions); the poor could have greater physical limitations because of their income, or their limitations could diminish their work capacity and thus their income.

There is a sharp decline in the reported incidence of chest pains (lasting greater than thirty minutes) with income; 16 percent of the poorest men and 30 percent of the poorest women report having experienced chest pains in the past month lasting for more than half an hour, compared to 12 and 19 percent of those in the top income quartile.

However, the other health variables show that the gradient is much more complex, and in fact along some dimensions the gradient favors the poor, especially with regard to health risk factors. Men and women in the lowest 


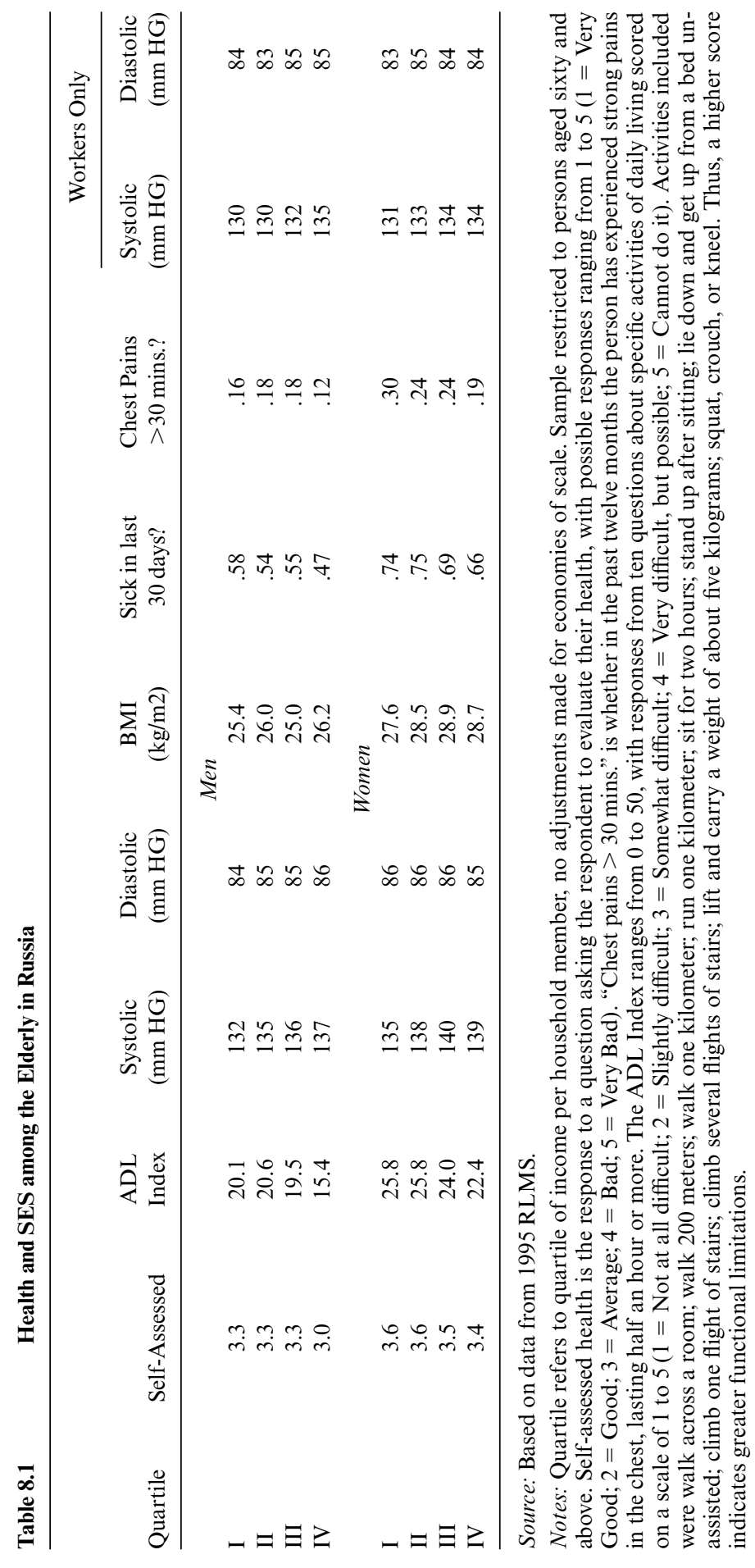


Table 8.2

Health Inputs/Behaviors and SES among the Elderly in Russia

\begin{tabular}{lcccc}
\hline Quartile & Drink? & $\begin{array}{c}\text { Amount drink, } \\
\text { if }>0(\mathrm{~g})\end{array}$ & Smoke? & $\begin{array}{c}\text { Amount smoke, } \\
\text { if }>0 \text { (g) }\end{array}$ \\
\hline I & \multicolumn{5}{c}{ Men } & & \\
II & .53 & 24.1 & .44 & 16 \\
III & .53 & 19.1 & .40 & 14 \\
IV & .62 & 23.9 & .39 & 14 \\
& .64 & 29.9 & .39 & 15 \\
I & & Women & & \\
II & .18 & 4.9 & .08 & 6.3 \\
III & .16 & 8.0 & .12 & 5.6 \\
IV & .27 & 5.7 & .13 & 6.7 \\
\hline
\end{tabular}

Source: Based on data from 1995 RLMS.

Notes: Quartile refers to quartile of income per household member, no adjustments made for economies of scale. Sample restricted to persons aged sixty and above.

income quartile have lower (4-5 $\mathrm{mm} \mathrm{HG}$ ) systolic blood pressure than those in the upper quartile; this could be due to a number of factors; for example, wealthier people may face more work-related stress. We will also see later, however, that the rich have higher levels of sodium intake and consume more fat, both of which would also be associated with higher blood pressure. Further, the incidence of drinking is higher among the wealthier (shown in the following). Part of the differences in blood pressure between rich and poor may be due to greater employment rates among the rich, which could affect blood pressure. ${ }^{5}$ In the final two columns of the table, we present data only on working persons; overall, systolic blood pressure is lower for those who are working compared to nonworkers, but we see that the working-poor still have lower blood pressure than the working-rich. These results are also interesting in light of the results in Jensen (2001), who finds that individuals who are more concerned about job loss (which typically the poor are) have higher blood pressure and are more likely to report having chest pains and other health problems.

The BMI data show wealthier individuals are also heavier than poorer persons, which is a health risk in itself and could also explain the higher blood pressure among the rich. However, the lower BMI of the poor could be related to illness, which in itself leads to lower income.

Table 8.2 presents information on behaviors that influence health, by in-

5. Though the direction of correlation is ambiguous, some work may create greater stress due to work-related responsibilities and pressures, or due to concern over job security. By contrast, the physical activities of work, provided it is not too strenuous, and the social contact provided could also have beneficial effects on blood pressure compared to being idle or spending most time alone. 
come quartile. For both men and women, the wealthy are approximately 10 percentage points more likely to say they have drunk alcohol in the past week and report drinking more the last time they drank. Smoking declines slightly with income for men, but the difference is small. There is no difference for either men or women in the number of cigarettes smoked, conditional on smoking.

Thus, overall, the relationship between health and SES needs to be seen as far more complex than simply stating that the poor are less healthy than the rich. The poor are less healthy on many outcome measures of health (mostly self-reported), but, for example, blood pressure and BMI are higher among the richest persons, which leads to increased risk of heart disease, stroke, and mortality. The important conclusion is that while there may be scope for policies to improve the health of the poor, policies should also not ignore the potential for improving the health of the wealthy.

\subsection{The Role of Nutrition}

We now turn to the issue of nutrition in the relationship between health and SES. One direct channel through which income may affect health is through nutrition. This channel is often overlooked in most settings of industrialized nations, where obesity is more of a concern than malnutrition. In fact, the Russian data are consistent with these observations, showing that obesity is very high, and the incidence of insufficient caloric intake is rare, even among the poorest.

However, proper nutrition is much more than adequate energy intake. While the exact linkages and magnitude of effects have not been precisely determined by medical researchers, it has long been understood that proper nutrition has a large effect on health. Energy (calories) is important for all aspects of functioning, but other nutrients (vitamins, minerals, and protein) are nearly as important, and long-term deficiency of certain nutrients can affect health through disease, or musculoskeletal maintenance. With age, people need fewer calories (energy from food), both because the basal metabolic rate (calories needed for involuntary work like breathing, heartbeat, and food digestion) declines, and because people tend to become less active. But while the elderly typically need fewer calories, they still need nearly the same amount of important nutrients such as protein, vitamins, and minerals.

To explore the role of nutrition in the relationship between health and SES, we first examine how diet varies with income, then how nutrition varies with diet, and then how nutrition affects health and physical functioning.

\subsubsection{From Income to Diet}

Table 8.3 presents data on dietary patterns by income quartile. For households in the various quartiles, we report raw quantities consumed on 
Table 8.3 Income and Nutrient Intake among the Elderly in Russia

\begin{tabular}{|c|c|c|c|c|c|c|c|c|c|}
\hline Quartile & $\begin{array}{l}\text { Meat/Fish/ } \\
\text { Eggs }\end{array}$ & Dairy & Bread & Cereals & Vegetables & Fruit & Fats & Sugar & $\begin{array}{c}\text { Borsch/ } \\
\text { Shchi }\end{array}$ \\
\hline \multicolumn{10}{|c|}{ Men } \\
\hline I & 102 & 125 & 219 & 93 & 242 & 45 & 17 & 31 & 401 \\
\hline II & 114 & 116 & 231 & 77 & 256 & 78 & 14 & 35 & 396 \\
\hline III & 114 & 116 & 231 & 77 & 258 & 78 & 14 & 35 & 396 \\
\hline IV & 159 & 160 & 246 & 73 & 280 & 66 & 15 & 40 & 357 \\
\hline \multicolumn{10}{|c|}{ Women } \\
\hline I & 60 & 107 & 168 & 62 & 209 & 69 & 10 & 30 & 285 \\
\hline II & 57 & 97 & 169 & 76 & 187 & 57 & 12 & 29 & 277 \\
\hline III & 69 & 122 & 162 & 72 & 204 & 74 & 13 & 32 & 260 \\
\hline IV & 90 & 156 & 159 & 80 & 244 & 85 & 10 & 33 & 268 \\
\hline
\end{tabular}

Source: Based on data from 1995 RLMS.

Notes: See table 8.2.

a daily basis, in grams, for ten food groupings. ${ }^{6}$ Overall, for both men and women, the largest categories of consumption by weight are borsch/shchi (a vegetable soup), bread and vegetables, and much smaller quantities of fruit and cereals. But additionally, the diets of the rich and the poor differ noticeably. While the rich eat more of most every food group except borsch/ shchi, there is a difference across the various food groups in how much more they consume. For men, the wealthiest quartile consume fifty-seven more grams (56 percent) of meat per day than the poorest, fifty-nine more grams (21 percent) of fruits and vegetables (combined), and thirty-five grams (28 percent) more dairy. On the other side, daily consumption of borsch/shchi is forty-four grams (11 percent) lower for the wealthy, and cereals are twenty grams ( 22 percent) lower. For women, the largest differences between the top and bottom quartiles are that the rich consume more dairy (forty-nine grams, 46 percent), and meat (thirty grams, 33 percent). Borsch/shchi is seventeen grams (6 percent) lower for the richest women, but most other categories are largely the same.

The upper half of table 8.5 presents estimates of elasticities from regressions of quantities consumed of the various foods on total household expenditure per person, whereas additional regressors that we include are age, gender, education, family size, and twenty-five food price variables, gathered from community-level price surveys. We estimate the regressions, both cross-sectionally (columns [1] and [3]) and while exploiting the panel nature of the data, to regress changes in consumption on changes in income. The results confirm what is observed in the data in the previous

6. An important issue, which we do not treat here, is quality substitution within food categories. See, for example, Subramanian and Deaton 1996. 
tables on means, namely that the largest positive elasticities are on meat, dairy, and fruit, and borsch/shchi has a large, negative elasticity. Another important lesson from this table is that the cross-sectional elasticities are very close to those obtained using the fixed-effects specification. If the elasticities were larger in cross section compared to changes, then we would be more likely to conclude that the differences in consumption patterns were due to other differences - in tastes or other attributes-between rich and poor (or that there is a degree of inertia in consumption, for example, due to habits). These results therefore suggest that economic resources are an important factor in the differential diets of rich and poor and that, with increases in income, diet changes in significant ways.

\subsubsection{From Diet to Nutrition}

From the food intake data, we can calculate daily intake of a variety of micro- and macro-nutrients by merging intake with Russia-specific conversion tables that list the nutrient content (approximately twelve macroand micronutrients) of nearly 2,600 individual food items. ${ }^{7}$ In addition, we also have information in the survey on whether individuals are taking specific vitamin or mineral supplements, which we can use to calculate total nutrient intake. ${ }^{8}$ Table 8.4 presents nutrient intake by income quartile, along with the (U.S.) recommended levels of daily intake for the elderly. ${ }^{9}$

The first thing to notice is that for all income groups, the intake of several key nutrients is well below recommended levels. For men, intake of niacin, vitamin $\mathrm{C}$, magnesium, potassium, and calcium are low. Women are low on intake of these same nutrients, as well as protein, thiamin, and riboflavin. Further, both men and women have extremely high daily sodium intakes.

In terms of the gradient with income, for men, higher income is associated with increased intake of important micronutrients such as calories, protein, niacin, vitamin $\mathrm{C}$, potassium, calcium, and iron. Women additionally increase intake of thiamin and riboflavin. However, for both men and women, increases in income are also associated with increased intake

7. The food items for which we have nutrient information are extremely detailed and match the level of detail provided in the food intake data. For example, there are entries for prepared and packaged foods; nearly thirty different entries for potatoes, which vary along several dimensions, including method of preparation (boiling, frying - for seven different types of oil/ lard); and entries for several hundred specific meals and entrees.

8. However, since we do not know the exact content of specific vitamin supplements, for persons who report taking vitamins we add to their daily intake the recommended daily level for the specific nutrient (we add the required amount for all nutrients if the person takes a multivitamin).

9. Guidelines are for individuals aged fifty or older, drawn from the 1997-1998 U.S. Dietary Reference Intakes, which includes Recommended Dietary Allowances (RDA) for thiamin, riboflavin, niacin, and magnesium and Adequate Intakes (AI) for calcium; 1989 RDA for energy, protein, vitamin A, vitamin C, and iron; 1995 Dietary Guidelines for Americans, published by the U.S. Department of Agriculture and the U.S. Department of Health and Human Services (for sodium). 


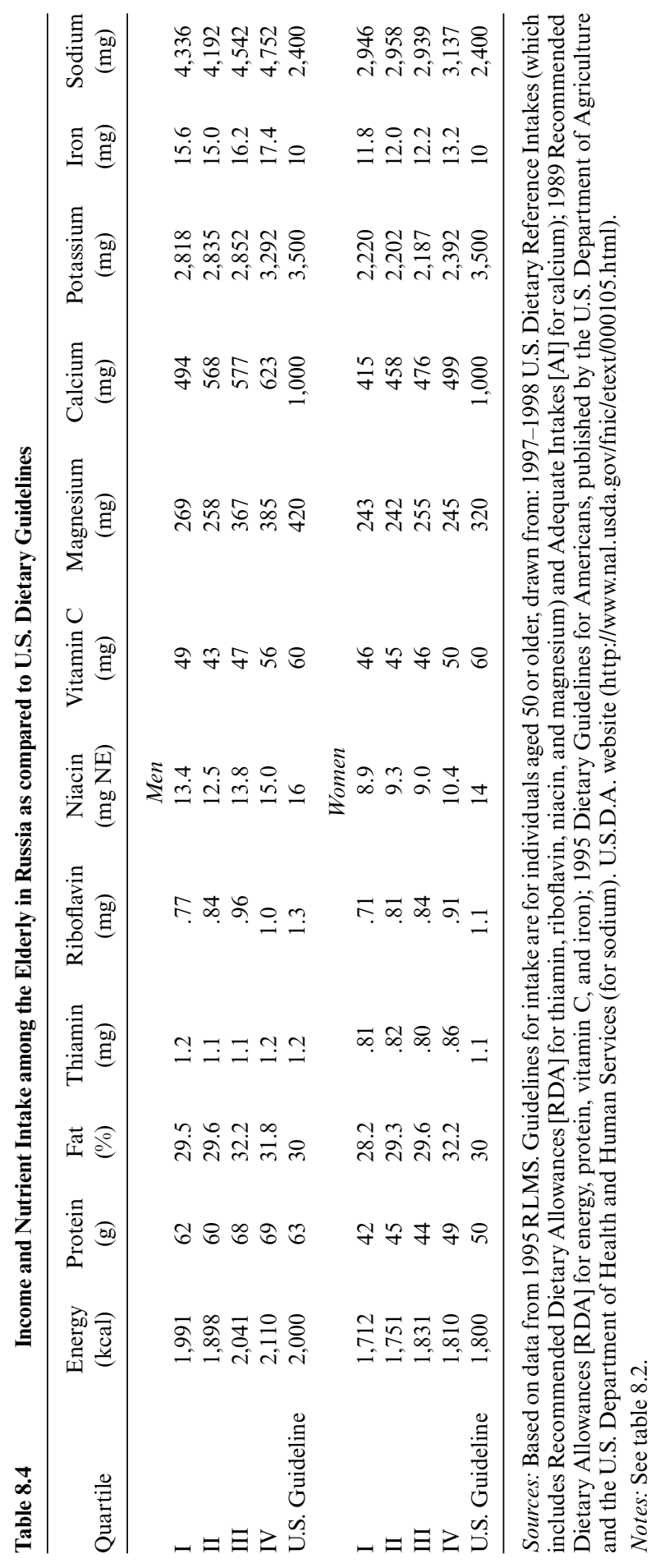


of sodium and a greater percent of calories from fat. Thus the wealthy have diets which yield more of several important nutrients, but the diets are less desirable from a health perspective in other ways.

It should be kept in mind that these data simply represent intake through food or vitamin supplements. The actual levels of the various vitamins and minerals available in a person's body may differ from these intakes for several reasons. First, the body can produce some nutrients (for example, the body can produce vitamin $\mathrm{D}$ through exposure to sunlight, though the elderly often have reduced time spent outside). Also, individuals vary in their ability to absorb vitamins. Furthermore, insufficient intake of some nutrients inhibits the absorption and effective use of other nutrients; for example, vitamin D is important for the body's ability to absorb calcium properly. There are also important interactions between nutrients; for example, an imbalance in the levels of potassium and sodium may be as harmful to blood pressure as simply an excess of sodium. Finally, it should also be mentioned that levels that vastly exceed the recommended levels could be just as harmful as deficiencies. For instance, the elderly are less able to effectively clear vitamin A from the body, and thus are at risk of vitamin A toxicity, which can lead to adverse reactions.

The lower half of table 8.5 provides estimates of the elasticities of intake of the various nutrients. For both men and women, the greatest elasticities are on the intake of calcium, fat, protein, vitamin C, and sodium. And as with consumption of foods, the cross-sectional and first-differenced elasticities are similar, suggesting income itself plays a role in the differential level of nutrient intake between the rich and poor. However, an important point which emerges from all of these results is that while nutritional status will improve (in some ways) with income, even large increases in income would not lead to completely adequate nutrition. The elasticities of many of the nutrients are quite small, and even among the wealthiest quartile, there are still deficiencies in the intake of calcium, potassium, magnesium, and vitamin $\mathrm{C}$ (for women). Therefore, it will take more than growth in incomes to arrive at adequate nutritional status among the elderly.

\subsubsection{From Nutrition to Health}

We saw earlier that on several measures, for instance, ADL's, the poor were less healthy than the rich. An important question we address now is whether the lower nutrient intake of the poor is directly associated with the lower health status of the poor. We focus on the particular case of the greater physical limitations of the poor, because the measure is slightly more objective than overall self-reported health status and because there is a clear link between the intake of certain nutrients and physical functioning, especially for the elderly. The macro- and micro-nutrients considered most important for maintenance of bones and muscles in old age, and thus those most likely to affect physical limitations, are protein-for muscle 
Table 8.5

Nutrient Elasticities with Respect to Expenditure

\begin{tabular}{|c|c|c|c|c|}
\hline & \multicolumn{2}{|c|}{ Men } & \multicolumn{2}{|c|}{ Women } \\
\hline & $\begin{array}{c}\text { Cross-Section } \\
\text { (1) }\end{array}$ & $\begin{array}{c}\text { First-Diffs. } \\
\text { (2) }\end{array}$ & $\begin{array}{c}\text { Cross-Section } \\
\text { (3) }\end{array}$ & $\begin{array}{c}\text { First-Diffs. } \\
\text { (4) }\end{array}$ \\
\hline \multicolumn{5}{|l|}{ Foods } \\
\hline Meat/Fish/Eggs & $.31 * * *$ & $.20 * * *$ & $.14 * * *$ & $.11 * * *$ \\
\hline Dairy & $.18 * *$ & $.14^{*}$ & $.28 * *$ & $.19 *$ \\
\hline Bread & $.12 * * *$ & $.10^{* *}$ & $.10^{* * *}$ & $.09^{*}$ \\
\hline Cereals & $-.06^{*}$ & .03 & .08 & -.02 \\
\hline Vegetables & $.11 * * *$ & $.19 *$ & $.09 * *$ & .08 \\
\hline Potatoes & -.08 & .03 & -.03 & .08 \\
\hline Fruit & $.16^{*}$ & $.10^{*}$ & $.14^{*}$ & $.13^{* *}$ \\
\hline Fats & .18 & $.10^{* *}$ & .10 & .08 \\
\hline Sugar & $.04 *$ & -.03 & $.09 * *$ & .02 \\
\hline Borsch/Shchi & $-.20 * *$ & $-.15^{* * *}$ & -.11 & $-.10^{*}$ \\
\hline \multicolumn{5}{|l|}{ Nutrients } \\
\hline Energy (kcal) & $.14 * *$ & $.10^{*}$ & $.19 * *$ & $.15^{*}$ \\
\hline Protein $(\mathrm{g})$ & $.20 *$ & $.15^{*}$ & $.21 * * *$ & $.13^{* *}$ \\
\hline Fat $(\mathrm{g})$ & $.19^{*}$ & $.30 * *$ & $.28 * * *$ & $.25^{* *}$ \\
\hline Thiamin (mg) & .11 & .06 & .08 & .14 \\
\hline Riboflavin (mg) & $.19 *$ & .08 & .16 & .11 \\
\hline Niacin (mg NE) & .16 & .03 & .12 & .06 \\
\hline Vitamin C (mg) & $.19 * *$ & $.16^{* *}$ & $.12^{* *}$ & $.17^{* * *}$ \\
\hline Magnesium (mg) & $.16^{* * *}$ & $.20 * * *$ & .09 & .03 \\
\hline Calcium (mg) & $.29 * * *$ & $.41 * * *$ & $.31 * * *$ & $.22 * * *$ \\
\hline Potassium (mg) & $.13^{* *}$ & .08 & .08 & -.04 \\
\hline Iron $(\mathrm{mg})$ & .14 & .07 & .11 & .03 \\
\hline Sodium (mg) & $.18^{* *}$ & $.31 * * *$ & .09 & $.14^{*}$ \\
\hline
\end{tabular}

Notes: Numbers in the tables are elasticities from regressions where food or nutrient consumed (or changes in amount consumed) is the dependent variable, and age, gender, education, family size, and twenty-five food prices, obtained from community-level surveys.

***Significant at the 1 percent level.

**Significant at the 5 percent level.

*Significant at the 10 percent level.

maintenance, repair, and growth — and calcium, vitamin A, vitamin D (the latter of which we do not measure in our data), and possibly magnesiumfor maintaining bone density and strength. For example, there is in particular a well-established link between low calcium intake and osteoporosis, a loss of bone density/mass. The main sources of calcium are dairy products and dark, leafy vegetables, and the last section revealed that the poor consume much lower quantities of these foods.

In order to assess the effect of nutrition on physical functioning, we regress the level of the ADL index on the intake of these nutrients (this assumes that the intake in the survey adequately reflects typical nutrient intake over a longer period of time). We also include total calories consumed, 
because there is evidence that in the presence of calorie deficiency, protein will be burned as energy rather than being used for muscle maintenance and repair. Other control variables that we include are income, age, education, BMI, and whether the person smokes or drinks. We focus exclusively on nonworkers to eliminate some of the feedback from ADLs to health (alternate regressions that include workers and add hours worked to the regression yield similar results).

The results are presented in table 8.6. In the first and fourth columns, we see the basic result that higher income is associated with a better ADL functioning (that is, a smaller number for the index, signifying fewer limitations) for both men and women. There is also a decline with age, with a worsening of approximately three-quarters of a point for men and women with every year of age. In the second and fifth columns, we add nutrient intake. Additional protein, calcium, and vitamin A are all associated with statistically significant reductions in ADL limitations. The results suggest that an increased intake of $300 \mathrm{mg}$ of calcium per day (an eight ounce glass of milk) is associated with a reduced ADL index of 5 points for men, or roughly half a point for each of the ten measures, and 1 point for women.

Table 8.6 Effects of Nutrition on Change in Limitations to Daily Functioning

\begin{tabular}{|c|c|c|c|c|c|c|}
\hline & \multicolumn{3}{|c|}{ Men } & \multicolumn{3}{|c|}{ Women } \\
\hline & (1) & (2) & (3) & (4) & $(5)$ & (6) \\
\hline log income per capita & $\begin{array}{l}-.10 \\
(.065)\end{array}$ & $\begin{array}{l}-.062 \\
(.067)\end{array}$ & $\begin{array}{c}-.070 \\
(.25)\end{array}$ & $\begin{array}{l}-.12 \\
(.061)\end{array}$ & $\begin{array}{c}-.084 \\
(.074)\end{array}$ & $\begin{array}{l}-.12 \\
(.104)\end{array}$ \\
\hline Age & $\begin{array}{c}.88 \\
(.30)\end{array}$ & $\begin{array}{l}.60 \\
(.22)\end{array}$ & $\begin{array}{c}.69 \\
(.30)\end{array}$ & $\begin{array}{c}.73 \\
(.22)\end{array}$ & $\begin{array}{l}.64 \\
(.044)\end{array}$ & $\begin{array}{l}.70 \\
(.054)\end{array}$ \\
\hline Calories & & $\begin{array}{l}-.0020 \\
(.0012)\end{array}$ & $\begin{array}{l}-.004 \\
(.003)\end{array}$ & & $\begin{array}{c}-.004 \\
(.001)\end{array}$ & $\begin{array}{l}-.002 \\
(.0012)\end{array}$ \\
\hline Protein & & $\begin{array}{l}-.017 \\
(.010)\end{array}$ & $\begin{array}{l}-.004 \\
(.006)\end{array}$ & & $\begin{array}{l}-.04 \\
(.025)\end{array}$ & $\begin{array}{l}-.048 \\
(.034)\end{array}$ \\
\hline Calcium & & $\begin{array}{c}-.013 \\
(.007)\end{array}$ & $\begin{array}{c}-.018 \\
(.008)\end{array}$ & & $\begin{array}{c}-.006 \\
(.001)\end{array}$ & $\begin{array}{c}-.004 \\
(.001)\end{array}$ \\
\hline Vitamin A & & $\begin{array}{c}-.012 \\
(.008)\end{array}$ & $\begin{array}{c}-.015 \\
(.008)\end{array}$ & & $\begin{array}{l}-.018 \\
(.042)\end{array}$ & $\begin{array}{c}.031 \\
(.042)\end{array}$ \\
\hline Magnesium & & $\begin{array}{l}-.012 \\
(.019)\end{array}$ & $\begin{array}{c}-.021 \\
(.008)\end{array}$ & & $\begin{array}{l}-.003 \\
(.012)\end{array}$ & $\begin{array}{c}-.004 \\
(.002)\end{array}$ \\
\hline BMI & & & $\begin{array}{c}.45 \\
(.18)\end{array}$ & & & $\begin{array}{l}.62 \\
(.072)\end{array}$ \\
\hline Smokes? & & & $\begin{array}{c}2.3 \\
(1.2)\end{array}$ & & & $\begin{array}{c}5.3 \\
(3.0)\end{array}$ \\
\hline Drinks? & & & $\begin{array}{l}1.0 \\
(.70)\end{array}$ & & & $\begin{array}{l}2.2 \\
(.97)\end{array}$ \\
\hline Minutes exercise & & & $\begin{array}{c}-.021 \\
(.013)\end{array}$ & & & $\begin{array}{l}-.013 \\
(.055)\end{array}$ \\
\hline No. of observations & 570 & 570 & 570 & 745 & 745 & 745 \\
\hline
\end{tabular}


The coefficient on income is also now much smaller and no longer statistically significant, because excluding nutrient variables created an omitted variable bias. In columns (3) and (6), we add in whether the person drinks or smokes and their BMI. As would be expected, drinking, smoking, and higher body weight are associated with greater declines in activity functioning. Calcium remains negative and statistically significant for both men and women. Some of the other minerals are no longer statistically significant individually, but an $F$-test reveals that we would not reject the hypothesis of the joint significance of protein, vitamin A, and magnesium at conventional levels of significance.

\subsection{Conclusion}

The problem of correlation between poverty and poor health exists for Russia as elsewhere. Numerous studies have documented this relationship for other countries. However, the relationship is not entirely onedimensional, and along some dimensions the wealthy are worse-off than the poor, or face greater health risks. There are numerous empirical problems which can't be overcome with existing data. However, exploring the specific channels linking SES and health, such as nutrition, provides insight on where to investigate further for causal links.

There are several important directions along which future research should proceed: First, for the SES-health link, the main objective now should be to focus on the implications for policy. The general implications of this research so far have been too broad; as mentioned previously, there are numerous reasons why the health of the poor can be worse than that of the rich. And each of these mechanisms implies different corrective policy instruments. This holds for the results of this paper as much as any other; assessing that nutrition plays a role in the disparities in health between rich and poor focuses the search for policy prescriptions somewhat, but also yields the need for further investigation. The important factor for policymakers to determine is whether the differences in nutritional intake are due to the relative costs of foods and thus the ability to afford proper nutrition; preferences (and especially the tradeoff between nutritional and nonnutritional attributes of food); knowledge; quality of medical advising with emphasis on diet; willingness to sacrifice/forgo nonnutritional attributes of food for nutritional content; or possibly some other reason. In the present case, the estimates of the elasticities from the panel data closely match those using cross-sectional variation, suggesting that with changes in income, the current poor would consume like the current rich, which will both improve their health in some ways, but hurt it in others.

From a methodological perspective, there is also a need for more research on how to correctly measure the quantities of interest. For health, 
this means greater analysis of the validity of subjective or self-reported measures, and the increased use of physically measured quantities or survey questions that are less subject to differences in interpretation or reporting. Likewise, measuring SES requires additional research; most studies in this literature assume that all income is pooled within households, so household income per person (or perhaps adjusted for economies of scale or adult equivalents) is used to represent access to resources by individuals. An exception is Case (chap. 7 in this vol.), who directly examines income pooling within households and the implications for health. This line of inquiry is related to research on intrahousehold decision making bargaining, and income pooling. The results from some of the literature in this field tell us that distribution within households is important for understanding the well-being of the elderly. We need additional survey methods and new data that gather more information on what goes on inside households.

\section{References}

Case, Anne, Darren Lubotsky, and Christina Paxson. 2002. Economic status and health in childhood: The origins of the gradient. American Economic Review 92 (5): $1308-34$.

Feinstein, Jonathan. 1993. The relationship between socioeconomic status and health: A review of the literature. The Milbank Quarterly 71:279-322.

Hurd, Michael, Daniel McFadden, and Angela Merrill. 1999. Predictors of mortality among the elderly. NBER Working Paper no. W7440. Cambridge, Mass.: National Bureau of Economic Research, December.

Jensen, Robert T. 2001. Job security, stress and health. Harvard University, John F. Kennedy School of Government. Mimeograph.

Jensen, Robert T., and Kaspar Richter. 2001. Understanding the relationship between poverty and children's health. European Economic Review 45 (4-6): $1031-39$.

2003. The health implications of Social Security failure: Evidence from the Russian pension crisis. Journal of Public Economics, forthcoming.

Meara, Ellen. 2001. Why is health related to socioeconomic status? NBER Working Paper no. W8231. Cambridge, Mass.: National Bureau of Economic Research, April.

Smith, James P. 1999. Healthy bodies and thick wallets: The dual relation between health and socioeconomic status. Journal of Economic Perspectives 13:145-66.

Smith, James P., and Raynard Kington. 1997a. Demographic and economic correlates of health in old age. Demography 34 (1): 159-70.

1997b. Race socioeconomic status, and health in late life. In Racial and ethnic differences in the health of older Americans, ed. Linda Martin, G. Soldo, and J. Beth, 106-62. Washington, D.C.: National Academy Press.

Subramanian, Shankar, and Angus Deaton. 1996. The demand for food and calories. Journal of Political Economy 104 (1): 133-62. 


\section{Comment David M. Cutler}

Rob Jensen's paper is very interesting. It examines income and health in Russia, a country where income variability and health differences between rich and poor are large. Jensen's data are clear, his analysis sound, and his results intriguing.

Indeed, Jensen may even underestimate the importance of his results. At the time of economic transition in Russia, mortality rates increased by staggering amounts. Between 1990 and 1994, male life expectancy at birth fell from sixty-four to fifty-eight years, and female life expectancy fell from seventy-four to seventy-one years. This is an enormous regression, the likes of which the world may never have seen before, at least not in the modern era.

A natural question arises - how much of this setback is a result of people getting poorer as the economy became turbulent, and how much is a result of other factors? The start to answering this question is to understand how and why income affects health. There are other questions as well: What type of social safety net can prevent such situations? What explains the difference between the experience of Russia and other Eastern European countries who went through transition with much less difficulty?

I interpret Jensen's results slightly differently than he does. Jensen shows that when looking at physical measures of health, the rich are in better health than the poor. For example, the rich have fewer ADL impairments than the poor, they have higher self-reported health status, and they report fewer incidents of chest pain in the previous thirty days. Jensen does not examine mortality differences between rich and poor, which could confirm and supplement these measures, but he could do so.

But when Jensen looks at the risk factors that would lead to health differences, he finds no clear message. The rich have better nutrition than the poor, but have worse risk factors along other dimensions. Blood pressure is higher for the rich than the poor, and the rich smoke more than the poor. Jensen finds that in total, risk factors do not explain much of the link between income and health. Only 30 percent of the effect of income on health for men is explained by this wealth of risk factors, and none of the link for women. The average effect is thus about 15 percent. At the end of the day, these results do not tell us much in total about why income and health status are linked in Russia. It is not that nothing matters, just that what matters does not paint a clear picture. Unfortunately, these results also make it more difficult to know how to interpret the link between income and

David M. Cutler is professor of economics in the Department of Economics and the John F. Kennedy School of Government, Harvard University, and a research associate of the National Bureau of Economic Research. 
health, and how to explain the Russian mortality crisis at the time of privatization.

The issue that this research faces is how to answer the pressing question - why do the rich have better health than the poor? Jensen has made a start, but I think he can push further. I have several comments about the data employed and the results presented that are intended to aid in this effort.

First, Jensen does not look at disease onset. One theory about the link between income and health is that richer people are less likely to develop severe conditions, perhaps because they have a better risk factor profile. A second theory is that the rich are less impaired by the same diseases than the poor. Perhaps they have better access to medical care, they can afford nonmedical goods that improve health, or they have better social situations that allow them to recover from disease more rapidly.

Jensen shows that the risk factor explanation is not entirely supported in the diseases he looks at. But Jensen has just a subset of the relevant risk factors. This is not to be critical. Measuring risk factors is complex, and we don't even know all the risk factors for disease. So any set of data is by necessity a subset of the true risk factors. Still, it is important to keep this in mind.

One way to differentiate these explanations is to look at the incidence of disease and health conditional on disease separately. The risk factor explanation argues that rich people should be less likely to experience serious diseases such as heart attacks, strokes, or cancers. The alternative is that the rich are less impaired when they have these diseases. I believe doing this decomposition is possible using the data that Jensen has, and it would be a welcome addition.

Jensen may be able to go even further. For example, other data might indicate how the rich and poor are treated in the medical sector when they have certain diseases. This would allow us to learn whether the medical system explains part of the link between income and health.

The second comment is that it would be nice to have more information on the quality of the data. The data on food and nutrition come from diet surveys that people fill out. They are self-reported surveys kept for two days. Such a methodology is common to many countries, including the United States. But it is not without problems. In the United States, for example, diet surveys indicate that the average woman consumes about 1,500 calories per day and the average male consumes about 2,500 calories per day. This is far below levels of caloric intake consistent with stable weight, even in a time period in which weight has been increasing rapidly. The diet surveys are underreporting average consumption by a substantial amount.

I should note that underreporting is not the same as lying. The act of keeping a diary may induce people to consume less than they would other- 
wise. We do not know how much of the underreporting is lying, misrecording of information, or behavioral change in response to keeping the diary. What we do know is that those nutrition totals almost certainly cannot be correct for the average person on the average day.

I have no idea if the Russian data is better or worse than the U.S. data. Reported caloric intake for women is higher in Russia than in the United States, but reported caloric intake for males is lower. One would need to compare these caloric intakes to changes in weight to see if they make sense. Jensen should be able to do this. It would add enormously to the credibility of the findings.

There is another data quality issue worth addressing. It is not clear to me that the data record the true quality of the food consumed, even if the food intake is correctly reported. For example, one hears stories about the brewing of homemade vodka in bad economic times. Such vodka may be far worse for health than commercially sold vodka. I don't know if the survey is able to capture this. The same is true potentially about all of the food measures. Is meat the same for the rich and poor? What about borsch? Jensen notes that the survey has more than one category for each food item, but in the U.S. context these are typically different items of food (hamburger versus steak, for example), not different qualities of the same item. Maybe the beef consumed by the poor is lower quality than the beef consumed by the rich, even when officially the same type of meat? More information about the quality of the food consumed is clearly warranted. Given how different the observable measures of nutrition are by income, the unobservable differences may be just as great.

The final comment is that Jensen should look at additional risk factors to see how they relate to income. Several factors come to mind that may explain the difference in health between rich and poor. First, the poor might experience more stress than the rich. Jensen has shown in other work that increased stress from the privatization of industry increases blood pressure, which may explain some of the overall increase in mortality during the transition. Stress may also differ cross-sectionally, with the poor facing more stress than the rich.

A second risk factor is the nature of jobs. Lower income people have different jobs from higher income people that may directly influence their health. For example, blue collar workers may naturally have more ADL impairments than white collar workers because they work in manual jobs, and this may be correlated with income. Jensen has information about the jobs that people are employed in and could control for this.

A third risk factor is the environment. Is the person living in a polluted or clean area? What infectious diseases are or were in the area? This again may influence health and is likely to differ systematically between rich and poor. There are almost certainly other risk factors that are relevant in the Russian context that would be interesting to explore. 
I do not know if any of these factors will explain the link between income and health that Jensen finds. But the issue is an important one, with potential applications for Russia, Eastern Europe, and developed countries more generally. More exploration on why income is related to health and what this says about economic transition could enhance research and policy making in many contexts. 
